\title{
Indirect estimation of student marijuana consumers population in Hamadan using PRM and NSU methods
}

\author{
Leyla Halimi ${ }^{1}$, Mohammad Babamiri ${ }^{2}$, Yadollah Hamidi ${ }^{3}$, Reza Majdzadeh ${ }^{4}$, Ali Reza Soltanian $*^{5}$ (D) \\ Received: 10 Nov 2019 \\ Published: 30 Nov 2020
}

\begin{abstract}
Background: Finding social causes of a particular disease or specific health problem in groups or hidden illnesses, such as drug misuse is difficult. To estimate the population size, it should be taken into account that under enumeration usually occurs in direct estimation of population of certain high-risk groups. The present study used indirect methods to accurately estimate the population of students who have once experienced marijuana abuse.

Methods: This cross sectional research was conducted on 461 students in Hamadan. Two indirect methods, the Network Scale-up (NSU) and proxy respondent method (PRM), were used. Data were analyzed by statistical tests and SPSS version 16 and Excel.

Results: The mean age (standard deviation) was 22.51 (4.19 years), and the prevalence of marijuana misuse was $1.94 \%, 4.12 \%$, and $2.6 \%$, respectively, in girls and $14.57 \%, 12.58 \%$, and $10.4 \%$ in boys using NSU, PRM, and direct method.

Conclusion: Direct and NSU methods had higher bias than PRM, the frequency of PRM was closer to reality, and the once use prevalence of marijuana was higher in the young male population than in the female.
\end{abstract}

Keywords: Social network, Indirect estimation, Marijuana consumer, Network scale-up (NSU), Proxy respondent method (PRM)

Conflicts of Interest: None declared

Funding: Hamadan University of Medical Sciences

*This work has been published under CC BY-NC-SA 1.0 license.

Copyright $@$ Iran University of Medical Sciences

Cite this article as: Halimi L, Babamiri M, Hamidi Y, Majdzadeh R, Soltanian AR. Indirect estimation of student marijuana consumers population in Hamadan using PRM and NSU methods. Med J Islam Repub Iran. 2020 (30 Nov);34:160. https://doi.org/10.47176/mijiri.34.160

\section{Introduction}

Studies indicate the prevalence of marijuana misuse is increasing in the United States. This figure was $4 \%$ in 2001-2002 and 9.5\% during 2011 to 2013 (1). Marijuana is now the most illegal drug at universities and its consumption is increasing among students. A study estimated that $46.6 \%$ of students used marijuana during their lives and reported $19.4 \%$ of marijuana misuse in the past 30

Corresponding author: Dr Ali Reza Soltanian, soltanian@umsha.ac.ir

1. Clinical Research Development Unit of Shahid Beheshti Hospital, Hamadan University of Medical Sciences, Hamadan, Iran

2. Department of Ergonomics, School of Public Health and Research Center for Health Sciences, Hamadan University of Medical Sciences, Hamadan, Iran

3. Department of Health Management and Economics, School of Public Health and Research Center for Health Sciences, Hamadan University of Medical Sciences, Hamadan, Iran

4. Community-Based Participatory-Research (CBPR) Center, Tehran University of Medical Sciences, Tehran, Iran

5. Department of Biostatistics \& Epidemiology and Research Center for Health Sciences, School of Public Health, Hamadan University of Medical Sciences, Hamadan, Iran days (2). In another study on students, almost $30 \%$ of students reported they used marijuana when they entered the university. Among students, who never used marijuana before university, $8.5 \%$ used it during the first year of study in university. It was also found living on campus was more likely related to start of misusing marijuana during the first year of study (3).

$\uparrow$ What is "already known" in this topic:

Finding social causes of a particular disease or a specific health problem in groups or hidden illnesses such as drug misuse is difficult. It is difficult to find the social causes of a particular disease or a specific health problem in hidden groups or diseases such as drug abuse. In estimating population size, underestimation usually occurs in direct estimation of certain high-risk groups.

$\rightarrow$ What this article adds:

In this study for the size estimation of marijuana users in students, we found that direct and NSU methods might underestimate the results. However, the frequency of use in PRM method was closer to the reality; and the prevalence of one time use of marijuana was higher in the young male population than in the female. 
In a study by Goldhil-Hoyt et al, it was found that $29 \%$ of 30-day marijuana users used it before others drugs, and $34 \%$ of them started marijuana regularly at the age of 18 or after entering university. The consumption of marijuana and other illegal drugs has increased in most student groups of US universities and a variety of universities. This increase may be due to the increased misuse by this group at high schools. However, almost a third of students began using marijuana at university and one third regularly used it. Intervention efforts should be made for school and university students (4).

According to the global report, the prevalence of addiction is $2.8 \%$ in the population aged 15 to 64 years in Iran (5). There is no accurate estimate of population of addicts in Iran due to the limited use of direct methods (6). However, studies have been conducted on specific populations, including high school students, indicating $1.6 \%$ of girls and $8 \%$ of boys had at least one experience of drug misuse (7). Another study on the Iranian students indicated the prevalence of smoking, opium, alcohol, psychotropic tablets, cannabis, heroin was $14.4 \%, 2.8 \%, 1.2 \%, 1.1 \%$, and $0.8 \%$, respectively (8). Another study on Iranian high school students found that marijuana misuse was $1 \%$ and the prevalence of its recent misuse was $0.8 \%$ (9).

As described in the fifth version of Diagnostic and Statistical Manual of Mental Disorders (DSM-V), marijuana is a mixture of small flowers, leaves and stems of cannabis, which is itself a hemp and marijuana plant. For centuries, marijuana has been used as a medical herb. By the end of the 19th century, cannabis was considered as antianxiety, antidepression, and gastrointestinal disorder drug in the United States. The complications of this drug include disorders in the respiratory and neurological systems, and above all the main mood change and anxiety (10).

Unlike direct methods, indirect methods help us estimate the size of the target population without asking the samples directly. The capture-recapture method is one of the indirect methods that estimates the size of the population by evaluating the number of individuals who were captured in at least 2 independent samples (11-13). Multiplier technique is another alternative method that requires a sample of a target population with specific information $(14,15)$. Although the concepts of these 2 techniques are easy to understand, their application is limited because we sometimes cannot find suitable examples and their assumptions are not met in some settings (11). Therefore, capture-recapture and multiplication techniques are not used in all settings $(14,16)$. One indirect method is to replace the network scale-up method (NSUM), which is the only real indirect technique, as in this type of study, we do not talk directly to the person or persons we are targeting, and we ask friends and acquaintances about them. The basic principle of NSU is that individual social networks represent the general population, and the descriptions of these networks describe the characteristics of the general population. More specifically, the proportion of individuals belonging to a subgroup in the network of a representative sample is directly related to the actual size of that subgroup in the general population (17).
Indirect methods, such as the network scale-up method (NSUM), capture-recapture method, and multiplier model have been used in recent years due to the difficulty of estimating social hidden or out-of-reach populations such as drug users. The use of direct methods is costly and timeconsuming and requires a large sample size and much manpower and may result in the under enumeration. Furthermore, these estimates may be unreliable for diseases or problems with a low and rare prevalence $(18,17,15)$. On the contrary, indirect methods do not have such executive problems $(11,7)$. The network scale-up method (NSUM), as a method of estimating sizes of hidden populations, has the following advantages $(20,19)$ :

1. There is no need for direct contact with members of subpopulations.

2. It is possible to estimate many groups or diseases by a single study.

3. The obtained results of this method are comparable at different times.

$$
\mathbf{e}=\mathbf{m} / \mathbf{c} * \mathbf{t}
$$

where (e) is the estimated size of the key population (such as sex workers or injecting drug users), (m) the number of key community members identified by the audience, (c) the size of the estimated social network responds, and (t) is the total population of the country (21).

To estimate the size of a personal network using a known population approach, each audience is asked about the number of people connected to them in a population of a known size (21).

It is assumed social media participants from a random sample (respondents) can represent the study population $(21,22)$. PRM is another indirect way to estimate the size of hidden groups without having to estimate the size of the social network. In this method, a random sample of respondents (proxy respondents) is asked about the behaviors of a selected group of people (alters) they know. It is assumed a random sample of selected and changing respondents is a sample of the community (22).

Kanato et al found the NSU method is cost-effective and efficient. People who inject drugs were 0.24 by the NSU method in this study. There was a difference of 5.8\% between this method and subgroups of injection addicted reference population (23).

The NSU method has been widely performed with promising and applied results in various studies in the world (24).

The overall health of the Iramian population depends on controlling the high-risk behavior, such as the youth addiction. Therefore, the correct estimation of sizes of such subgroups is the key to information for planning, monitoring, and evaluating prevention programs and a health priority for policymakers. Therefore, the present study was partially and locally designed to solve this gap. This study aimed to estimate the prevalence of marijuana misuse among Hamadan students during 2016 using the hidden estimation method.

\section{Methods}

This cross sectional study was conducted among the youth in Hamadan and in a subgroup of students. A ran- 
dom sample of 500 students was selected using the multistage random sampling (stratified sampling and random sampling) as a ratio at universities and classrooms; and questionnaires were completed by trained students (Appendix 1).

In universities, samples were randomly selected from 2 groups of medical and nonmedical universities. The proportion of students from different fields and universities was considered in the selection of samples. Incomplete questionnaires were excluded and finally 461 completed questionnaires were selected for evaluation. Given the cultural issues in the Iranian society, it was decided to consider friends of the same gender in the present study and reliability and validity were also investigated.

As mentioned earlier, the NSU and PRM are 2 methods of indirect estimation of population (25). The questionnaire consisted of 4 sections, including demographic questions related to the NSU method, PRM, and direct method about the one's own behavior. Based on the literature review, the main focus is on the active network (An active network means that a person is actively communicating with these people (by telephone, face to face, email, or any other communication method) in a study on the NSU $(26,20,19)$.

In the PRM, names of 30 girls and 30 boys with unique pronunciation were selected by referring to Hamadan Organization for civil registration, so that selected names should have the following conditions according to principles of choosing names in the PRM:

1. The name should not be common in both sexes.

2. Names should not have different pronunciations and types.

3. Names should not have 2 or combined names.

4. One percent of the most common names and $1 \%$ of the lowest common names should not be among other names.

Names were written on cards and distributed by the questionnaire with training while questionnaires were completed. Male respondents were asked to choose cards with male names, and similarly women were asked to choose cards with female names. They were then asked to select the most possible people with the chosen names in their social networks and respond to questions about them by PRM. For the direct method, the questions were asked directly at the end of the questionnaire. The answer to all questions of the questionnaire was optional. Data were entered into SPSS software after encoding and analyzed using Pearson chi-square and Fisher's exact test; and significance level was set at 0.05 .

\section{Inclusion criteria}

This study selected students who were at least in the second semester and their communication networks were formed during the last semester.

\section{Exclusion criteria}

The first and second semester students were excluded from the research due to the noncommunication networks among them. Furthermore, students who were not willing to cooperate and respond to questionnaires were also excluded from the research.

\section{Results}

Researchers could analyze data of 461 students. The mean (SD) age of the students was 22.51 (4.19) years and $58.1 \%$ were female. Almost $409(88.7 \%)$ of the students were single and $320(69.3 \%)$ resided in dormitories. A total of $408(88.4 \%)$ students were studying at Hamadan universities for at least 2 years, and all of them were studying for a semester with their classmates leading to the creation of a social network among them. C number was 25.8 and 29.5 for male and female students, respectively.

\section{Estimating prevalence of marijuana misuse in both} genders

The prevalence of marijuana was $1.94 \%$ with the NSU method and $4.12 \%$ with the PRM, and the prevalence of consumption was $2.6 \%$ in the direct method (Table 1 ). The frequency percentages of marijuana consumption were $14.57 \%, 12.58 \%$, and $10.4 \%$ in boys with the NSUM, PRM, and direct method respectively (Table 1). The percentage of misuse was lower in both genders $(0.82$ for boys and 0.63 for girls) in the direct method than the PRM. The percentage of prevalence was higher in boys than in girls (1.16 vs. 0.48$)$ with the NSU method compared to the PRM.

\section{The proportion of marijuana misuse in boys to girls}

Marijuana misuse proportions were more in male students compared to females, with $7.51 \%, 3.05 \%$, and $4 \%$ respectively, based on NSUM, PRM, and direct method. Table 1 demonstrates the results of frequency of marijuana student consumers in age, gender, education level, and job groups using NSUM and PRM.

According to research findings, no significant difference was found between the prevalence of one-time misuse of marijuana in male and female students for age group, field of study, education level, and type of job by the NSU method (Table 2).

Findings revealed a significant difference between the

Table 1. Estimation of frequency percentage of at least one-time consumption of marijuana in terms of gender and research method in students at Hamadan universities

\begin{tabular}{lccccc}
\hline Gender & \multicolumn{3}{c}{ Method (\%) } \\
\cline { 2 - 6 } & PRM & NSU & Direct & NSU Vs. PRM & Direct method Vs. PRM \\
\hline Male & 12.58 & 14.57 & 10.4 & 1.16 & 0.82 \\
Female & 4.12 & 1.94 & 2.6 & 0.48 & 0.63 \\
\hline
\end{tabular}


Table 2. Frequency distribution (percentage) of marijuana misuse in students based on age groups, education level and major and in terms of gender according to NSUM and PRM

\begin{tabular}{|c|c|c|c|c|}
\hline \multirow[t]{2}{*}{ Method } & \multirow[t]{2}{*}{ Major } & \multicolumn{2}{|c|}{$\begin{array}{l}\text { At least once used marijuana } \\
\text { Quantity (Percent) }\end{array}$} & \multirow[t]{2}{*}{$\mathrm{p}$} \\
\hline & & No & Yes & \\
\hline \multirow[t]{2}{*}{ NSU } & $\begin{array}{l}\text { Bachelor and lower } \\
\mathrm{N}=268\end{array}$ & $168(62.7)$ & $100(47.3)$ & 0.064 \\
\hline & $\begin{array}{l}\text { Master and higher } \\
\qquad \mathrm{N}=193\end{array}$ & $129(66.8)$ & $64(31.2)$ & \\
\hline \multirow[t]{2}{*}{ PRM } & $\begin{array}{l}\text { Bachelor and lower } \\
\qquad \mathrm{N}=268\end{array}$ & $221(82.5)$ & $47(17.5)$ & 0.971 \\
\hline & $\begin{array}{l}\text { Master and higher } \\
\qquad \mathrm{N}=193\end{array}$ & $163(84.5)$ & $30(15.5)$ & \\
\hline \multirow[t]{3}{*}{$\mathrm{NSU}$} & $\begin{array}{l}20 \text { years and less } \\
\mathrm{N}=158\end{array}$ & $114(72.2)$ & $44(21.8)$ & 0.872 \\
\hline & $\begin{array}{c}21-25 \text { years } \\
\mathrm{N}=255\end{array}$ & $153(60.0)$ & $102(40.0)$ & \\
\hline & $\begin{array}{l}25 \text { years and more } \\
\mathrm{N}=48\end{array}$ & $30(62.5)$ & $18(37.5)$ & \\
\hline \multirow[t]{4}{*}{ PRM } & $\begin{array}{l}20 \text { years and less } \\
\mathrm{N}=158\end{array}$ & $141(89.2)$ & $17(10.8)$ & 0.016 \\
\hline & $\begin{array}{c}21-25 \text { years } \\
\mathrm{N}=255\end{array}$ & $202(79.2)$ & $53(21.8)$ & \\
\hline & $\begin{array}{l}25 \text { years and more } \\
\qquad \mathrm{N}=48\end{array}$ & 419 (85.4) & 7 (14.6) & \\
\hline & Medical sciences & $105(63.3)$ & $61(36.7)$ & 0.059 \\
\hline $\mathrm{NSU}$ & $\begin{array}{c}\mathrm{N}=166 \\
\text { Non-medical sciences } \\
\mathrm{N}=295\end{array}$ & $192(65.1)$ & $103(34.9)$ & \\
\hline \multirow[t]{2}{*}{ PRM } & $\begin{array}{l}\text { Medical sciences } \\
\mathrm{N}=166\end{array}$ & $137(82.5)$ & $29(17.5)$ & 0.474 \\
\hline & $\begin{array}{l}\text { Non-medical sciences } \\
\qquad \mathrm{N}=295\end{array}$ & $247(83.7)$ & $48(16.3)$ & \\
\hline
\end{tabular}

prevalence of one-time misuse of marijuana in male and female students for the field of study, grade, and type of job based on PRM. Despite the fact that the percentage of frequency of misuse was higher in 21-25 years age group, there was no statistically significant difference between the prevalence of marijuana misuse in boys in age group based on the PRM, but this difference was significant in female students $(p=0.016)$ (Table 2$)$.

\section{Discussion}

In the present study the frequency of marijuana misuse among Hamadan university students was higher with the PRM than the other 2 methods, NSU and direct methods. This difference was also notably significant in terms of gender especially in the NSU method.

In this study the lowest prevalence of marijuana misuse was $2.6 \%$ in females by direct method, but the highest misuse was 14.575 in males by the NSU method. In a study titled "Correlates of college student marijuana use in US students in 1997", Bell et al found that the prevalence of misuse among students was $24.8 \%$, which was higher than the present study (27). This issue can be greatly important to policymakers for preventing drug addiction in the society.

In a study titled "Size estimation of groups at high risk of HIV/AIDS using network scale up in Kerman", Shokoohi et al reported highest incidence rates of $6.8 \%$ for the alcohol consumption, $4.7 \%$ for out-of-the norm sex, and 35 for the opium use (28). According to a study by Sal ganik et al, the use of indirect methods, such as NSU, indicates the higher prevalence of narcotic drugs than indirect methods or analysis with the secondary data (29).
Shamsi pour et al conducted a research in Tehran in 2015 and found the overall prevalence of drug misuse was $23 \%$ among students by the indirect CM method, while this prevalence was $3 \%$ by direct method (30).

In the present study, marijuana misuse was higher in male students than female students in all methods. Chen et al conducted a research titled "'Relationships between frequency and quantity of marijuana use and last year proxy dependence among adolescents and adults in the United States" and found marijuana misuse was not different in adolescent girls and boys, but it was higher among adult boys than adult girls (31).

There was a very high difference in marijuana misuse between girls and boys in the NSU method (Table 1), which may be due to the fact that high-risk behaviors such as addiction are not obvious among women in Iran due to their high social enormity; thus, they are underenumerated and very difficult to collect information on high-risk behaviors in women compared to men.

Despite the fact that the misuse of marijuana in both genders and different academic levels was higher in students with bachelor and associate degree than those with master, doctoral, and $\mathrm{PhD}$, this relationship was not statistically significant, indicating that although students' high education prevents them from consuming marijuana, the effect is not significant enough to make the relationship meaningful.

The research also indicated that the misuse of marijuana in the 21-25 age group was higher than the 20-25 age group in both genders.

According to a study by Bell et al titled "Correlates of college student marijuana use: Results of a US national 
survey" in 1997, marijuana use was compared in students in terms of age and it was found that marijuana use was 1.55 times more in students younger than 24 years than students aged 24 years and older. This result is consistent with the present study (27).

$\mathrm{C}$ was found equal to 28.73 and 28.89 in male and female students, respectively, indicating that every girl or boy student at Hamadan universities was communicating with 28 students of the same gender in their social networks on average, and this ratio was slightly different and almost similar between male and female students. This was a lower estimate than a research by Shokoohi et al (32) on the estimated size of the active network of Kermani men $(n=303)$, which may be due to differences in definitions of "communication and recognition". The present study referred to the recognition of classmates or friends of the same gender or university.

Sheikh zadeh et al conducted a research entitled "Comparing direct, network scale-up, and proxy respondent methods in estimating risky behaviors among 500 collegians in Kerman" and measured the size of social network of male and female students equal to 26 and 29 , respectively. The NSU method reported the alcohol consumption of $0.44 \%$ and $8.68 \%$, out-of-norm sexual relations of $95 \%$ and $48 \%$, injection drug addicts of $0 \%$ and $0.23 \%$, and heroin and cannabis use of $0 \%$ and $0.17 \%$ in women and men, respectively. PRM method reported the alcohol consumption of $2.32 \%$ and $18.12 \%$, out-of-norm sexual relations of $3.47 \%$ and $13.42 \%$, injection drug addicts of $39 \%$ and $0.67 \%$, and heroin and cannabis use of $0.38 \%$ and $2.01 \%$, and hashish use of $0.77 \%$ and $2.01 \%$ in women and men, respectively. It was also found that the PRM had less bias than other methods (33).

Given the difference in the prevalence of marijuana misuse in 3 different methods, it seems PRM has less bias and the obtained frequency was without any prevention, which was common in estimates of addiction studies, as the research question of this method only referred to a well-known person with a specific name; and the respondent focused on the same person and it was possible to answer correctly. In the NSU method, however, students should recall their friends in their minds and remember the exact number of people who used marijuana in their networks. Therefore, the phenomenon of underreporting in NSU may be significant due to the higher transmission error.

Incomplete questionnaires were also another problem with this project; thus, researchers decided to remove them. This study was also cross sectional and only investigated the one-time misuse of marijuana by students over the past year, but a longitudinal study can precisely indicate the consumption rate and model of this substance. Researchers suggest investigating this issue by conducting longitudinal studies with larger sample sizes.

\section{Conclusion}

After estimating the misuse of marijuana in students by comparing indirect and direct methods, it seemed direct and NSU methods had more bias than the PRM, which had a closer frequency to reality. One of the most effective factors in bias in the direct method is nonresponse due to social stigma or lack of willingness to report accurately. As the PRM might have the minimum information bias, our estimate of this population was obtained as a more accurate form than results of direct and NSU methods for gender. The proportion of this estimate (direct and NSU methods Vs. PRM) was a goal of this study as a correction factor in balancing results of direct and NSU. Results of the present study should be taken into account by health policymakers given the prevalence of one-time use of marijuana in a young population in Hamadan, especially in males which is much more than women and is likely to be a sample of estimates in the whole country.

\section{Limitations and suggestions:}

Given that addiction is a social stigma in any society, questions in this regard may be answered dishonestly. However, using an indirect method and having people comment on their friends reduces these errors to some extent. Nevertheless, the indirect method also has the limitation of reminding people of their friends' situation.

\section{Acknowledgment}

This research has been supported by Hamadan University of Medical Sciences and the Clinical Research Development Unit of Shahid Beheshti Hospital (code of ethics: IR.UMSHA.REC.1395.558).

\section{Conflict of Interests}

The authors declare that they have no competing interests.

\section{References}

1. Hasin DS, Saha TD, Kerridge BT, Goldstein RB, Chou SP, Zhang H, et al. Prevalence of marijuana use disorders in the United States between 2001-2002 and 2012-2013. JAMA Psychiatry. 2015;72(12):1235-42.

2. Page RM, Scanlan A. Perceptions of the prevalence of marijuana use among college students: A comparison between current users and nonusers. J Child Adolesc Subst Abuse. 2000;9(2):1-12.

3. Gledhill-Hoyt J, Lee H, Strote J, Wechsler H. Increased use of marijuana and other illicit drugs at US colleges in the 1990s: results of three national surveys. Addiction. 2000;95(11):1655-67.

4. Mojahed A, Bakhshani NM. Prevalence of smoking and drug abuse in students of Zahedan high schools. Zahedan J Res Med Sci. 2004;6(1):e95038

5. Drugs UNOo, Crime. World drug report 2010: United Nations Publications; 2010.

6. Dehghani K, Zare A, Dehghani H, Sedghi H, Poormovahed Z. Drug abuse prevalence and risk factors in students of Shaheed Sadoughi university of medical sciences, Yazid. J Shaheed Sadoughi Univ Med Sci. 2010;18(3):164-9.

7. Laska EM, Meisner M. A plant-capture method for estimating the size of a population from a single sample. Biometrics. 1993:209-20.

8. Vadivoo S, Gupte MD, Adhikary R, Kohli A, Kangusamy B, Joshua $\mathrm{V}$, et al. Appropriateness and execution challenges of three formal size estimation methods for high-risk populations in India. Aids. 2008;22:S137-S48.

9. Ahmadi J, Hasani M. Prevalence of substance use among Iranian high school students. Addict Behav. 2003;28(2):375-9.

10. Kandel D, Chen K, Warner LA, Kessler RC, Grant B. Prevalence and demographic correlates of symptoms of last year dependence on alcohol, nicotine, marijuana and cocaine in the US population. Drug Alcohol Depend 1997;44(1):11-29.

11. Hook EB, Regal RR. Capture-recapture methods in epidemiology: methods and limitations. Epidemiol Rev. 1995;17(2):243-64. 
12. Larson A, Stevens A, Wardlaw G. Indirect estimates of 'hidden'populations: capture-recapture methods to estimate the numbers of heroin users in the Australian Capital Territory. Soc Sci Med. 1994;39(6):823-31.

13. Stephen C. Capture-recapture methods in epidemiological studies. Infect Control Hosp Epidemiol. 1996;17(4):262-6.

14. Hickman M, Hickman M, Hope V, Platt L, Higgins V, Bellis M, et al. Estimating prevalence of injecting drug use: a comparison of multiplier and capture-recapture methods in cities in England and Russia. Drug Alcohol Rev. 2006;25(2):131-40.

15. Zhang D, Wang L, Lv F, Su W, Liu Y, Shen R, et al. Advantages and challenges of using census and multiplier methods to estimate the number of female sex workers in a Chinese city. AIDS Care. 2007;19(1):17-9.

16. HIV/AIDS JUNPo. Estimating the size of populations at risk for HIV. Geneva: UNAIDS. 2003.

17. Tate JE, Hudgens MG. Estimating population size with two-and three-stage sampling designs. Am J Epidemiol. 2007;165(11):1314-20.

18. Vandepitte J, Lyerla R, Dallabetta G, Crabbé F, Alary M, Buvé A. Estimates of the number of female sex workers in different regions of the world. Sex Transm Infect. 2006;82(suppl 3):iii18-iii25.

19. Bernard HR, Hallett T, Iovita A, Johnsen EC, Lyerla R, McCarty C, et al. Counting hard-to-count populations: the network scale-up method for public health. Sex Transm Infect. 2010;86(Suppl 2):ii11ii5.

20. Killworth PD, Johnsen EC, McCarty C, Shelley GA, Bernard HR. A social network approach to estimating seroprevalence in the United States. Soc Networks. 1998;20(1):23-50.

21. Center RB. Estimating the size of key populations at higher risk of HIV through a household survey (ESPHS) Rwanda 2011. Technical report, Calverton, Maryland, USA: RBC/IHDPC, SPF, UNAIDS and ICF ..., 2012.

22. McCarty C, Killworth PD, Bernard HR, Johnsen EC, Shelley GA. Comparing two methods for estimating network size. Hum Organ 2001:28-39.

23. Kanato M. Size Estimation of Injecting Drug Users through the Network Scale-Up Method in Thailand. J Med Assoc Thai. 2015;98:S17-24.

24. Shelley GA, Bernard HR, Killworth P, Johnsen E, McCarty C. Who knows your HIV status? What HIV+ patients and their network members know about each other. Soc Networks. 1995;17(3-4):189217.

25. Hickman M, Taylor C, Chatterjee A, Degenhardt L, HAY G, TILLING K, et al. Estimating the prevalence of problematic drug use. J Drug Educ. 2002:15.

26. Killworth PD, Johnsen EC, Bernard HR, Shelley GA, McCarty C. Estimating the size of personal networks. Soc Networks. 1990;12(4):289-312.

27. Bell R, Wechsler H, Johnston LD. Correlates of college student marijuana use: Results of a US national survey. Addiction. 1997;92(5):571-81.

28. Shokoohi M, Baneshi MR, Haghdoost A-A. Size estimation of groups at high risk of HIV/AIDS using network scale up in Kerman, Iran. Int J Prev Med. 2012;3(7):471.

29. Salganik MJ, Fazito D, Bertoni N, Abdo AH, Mello MB, Bastos FI. Assessing network scale-up estimates for groups most at risk of HIV/AIDS: evidence from a multiple-method study of heavy drug users in Curitiba, Brazil. Am J Epidemiol. 2011;174(10):1190-6.

30. Shamsipour M, Yunesian M, Fotouhi A, Jann B, Rahimi-Movaghar A, Asghari F, et al. Estimating the prevalence of illicit drug use among students using the crosswise model. Subst Use Misuse. 2014;49(10):1303-10.

31. Chen K, Kandel DB, Davies M. Relationships between frequency and quantity of marijuana use and last year proxy dependence among adolescents and adults in the United States. Drug Alcohol Depend. 1997;46(1):53-67.

32. Shokoohi M, Baneshi MR, Haghdoost AA. Estimation of the active network size of Kermanian Males. Addict Health. 2010;2(3-4):81.

33. Sheikhzadeh K, Baneshi MR, Afshari M, Haghdoost AA. Comparing direct, network scale-up, and proxy respondent methods in estimating risky behaviors among collegians. J Subst Use. 2016;21(1):9-13. 
Appendix 1

Topic of questioning: Comparing NSUM and PRM in determining the size of population of marijuana consumers (Cannabis-Weed)

Gender: Age: Education level: Job: Marital status: Residence (city- village):

Section 1: Participants' characteristics (without name)

- How many close friends do you have? Given the number of close friends, please answer the following questions by mentioning the number. Please write the number of your friends in this table.

Girl: ....

Boy: ...

Section 2: Questions about estimating the population size of marijuana (Cannabis-Weed) consumers by the NSU method

1- How many close friends of yours have consumed marijuana (Cannabis-Weed) at least once in the past year? Please write the number of your friends in this section.

Girl: ...

Boy: .

Section 3: Questions about estimating the population size of marijuana (Cannabis-Weed) consumers by the PRM

- Given the names, which you have selected from cards, please answer the following questions and write yes or no in the relevant section 1- Have you consumed marijuana at least once in the past year (Cannabis-Weed)?

Please answer "yes" or "no" in this section.

Girl: ...

Boy: ...

Section 4: Questions about participants

Please answer "yes" or "no" to the following questions.

1- Have you used alcoholic beverages such as vodka, whiskey, beer or wine at least once during the past year? 2- Have you used marijuana (Cannabis-Weed) at least once during the past year? If yes how many times?

The Number of marijuana misuse (Cannabis-Weed) during the past year: ...

We appreciate your cooperation. 